\title{
Early Experience with IV Iron Preoptimisation in Critical Ischaemia (Case Series)
}

Ahmed Nassar, Stacey Kerr, Bryce Renwick

Department of Vascular surgery, Aberdeen Royal Infirmary, Aberdeen, Scotland, United Kingdom. a.nassar@nhs.net

*Corressponding Author: Ahmed Nassar, Department of Vascular surgery, Aberdeen Royal Infirmary, Aberdeen, Scotland, United Kingdom.

\section{INTRODUCTION}

Pre-operative anaemia is present in approximately $30 \%$ of patients undergoing non-cardiac surgery ${ }^{1}$. The presence of pre-operative anaemia is the strongest predictor of perioperative blood transfusion and is an independent risk factor for post-operative morbidity and mortality. ${ }^{2}$ It is well known that Red Blood Cells (RBC) transfusion can increase the surgical length of stay, increase mortality in surgical patients, and expose patients to the risk of circulatory overload, acute lung injury, and immunosuppression. ${ }^{3-5}$ Sufficient data exist to support intravenous iron as efficacious and safe. Intravenous iron should be used as front-line therapy in patients who do not respond to oral iron or are not able to tolerate it, or if surgery is planned for $<6$ weeks after the diagnosis of iron deficiency. ${ }^{6}$. The European Medicines Agency concluded that the benefits of i.v. iron exceed the risks when used appropriately (correct indication and dose), without any difference in safety profile among available formulations. ${ }^{7} \mathrm{We}$ report three vascular cases had peri-operative i.v iron treatment for anaemia.

\section{CASE 1}

A 70 years old female patient was admitted for supracoeliac aortic-distal superior mesenteric artery (SMA) bypass using venous graft. She presented with massive weight loss, post-prandial pain and food fear. CT showed long occlusion of SMA and tight critical stenosis of the coeliac artery (figure 3). She started on IV iron infusion about 60 days before the surgery with $\mathrm{Hb}$ level $12.1 \mathrm{~g} / \mathrm{dl}$ and ferritin level $51 \mu \mathrm{g} / \mathrm{l}$. Hb level was $11.1 \mathrm{~g} / \mathrm{dl}$ a day before surgery and blood transfusion was not required in the perioperative period.

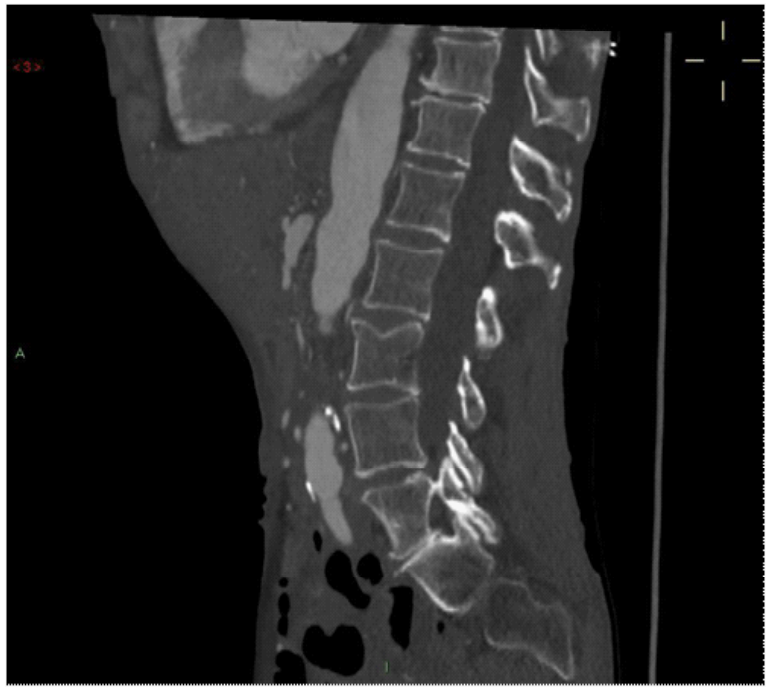

Figure 1

\section{CASE 2}

A 71 year-old female patient who was admitted as an emergency for critical limb ischaemia of the both lower limbs and presented with rest pain and tissue loss. A Computed Tomography (CT) angiography on admission showed Multilevel disease with severe aortic near occlusive disease, right common iliac and external iliac arteries occlusive disease, severe left common iliac and external iliac stenotic disease and bilateral common femoral artery (CFA) and superficial femoral artery (SFA) and popliteal artery disease (Figure 1). Her past medical history includes ischaemic heart disease, previous myocardial infarction, hypertension, osteoarthritis of the spine, partial gastrectomy for gastric ulcer and ex-smoker. The case was discussed in the vascular multidisciplinary team (MDT) meeting and the decision made to perform Aorto-bifemoral bypass and bilateral femoral endarterectomy. Her haemoglobin ( $\mathrm{Hb}$ ) level on admission was $10.3 \mathrm{~g} /$ $\mathrm{dl}$ and ferritin $202 \mu \mathrm{g} / \mathrm{l}$. She had IV iron infusion 
treatment for 11 days. Repeat $\mathrm{Hb}$ level was $11.2 \mathrm{~g} /$ $\mathrm{dl}$ on the day of the procedure and she did not need intra-operative nor post-operative blood transfusion.

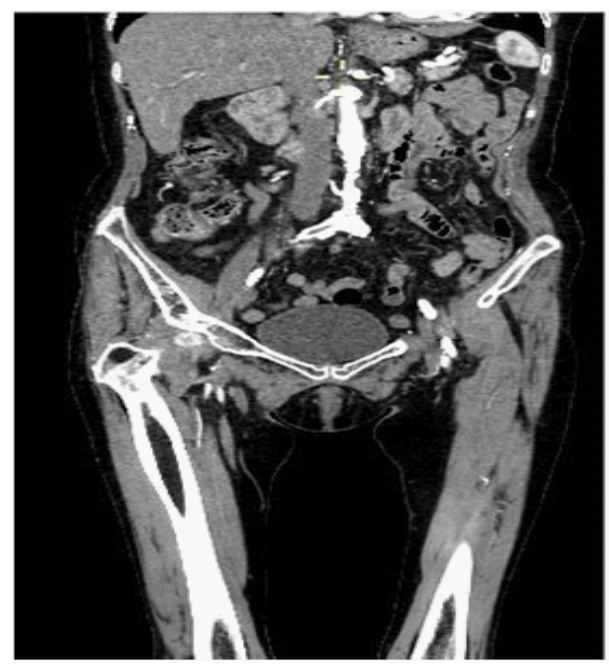

Figure 2

\section{CASE 3}

A 74 year-old female patient who was admitted for Left below knee amputation due to extensive circumferential gaiter's area ulceration, occluded femoropopliteal bypass (Figure 2) and severe pain. Her past medical history includes: Deep vein thrombosis, type 2 Diabetes mellitus, hypertension, pulmonary embolism, Ex-smoker and right below knee amputation. She was admitted only one day before surgery when she commenced IV iron infusion. $\mathrm{Hb}$ level on admission was $8.8 \mathrm{~g} / \mathrm{dl}$ and ferritin $101 \mu \mathrm{g} / \mathrm{l}$. She needed only one unit of packed red blood cells on post-operative day 2 because $\mathrm{Hb}$ level dropped to 7.3 $\mathrm{g} / \mathrm{dl}$. After wards, she continued oral ferrous fumerate $210 \mathrm{mg}$ twice daily and $\mathrm{Hb}$ level was $8.8 \mathrm{~g} / \mathrm{dl} 10$ days after this.

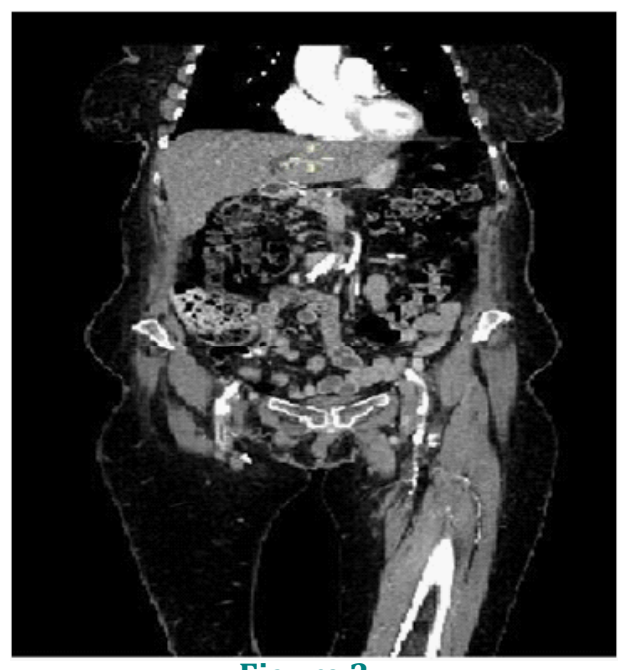

Figure 3

\section{DiscUSSION}

Several guidelines for the management of perioperative anaemia have been published over the last decade. However, for anaemia and iron deficiency in adult surgical patients, there are a number of nonevidence-based misconceptions regarding prevalence, consequences, diagnosis and treatment, as well as inconsistency of terminology and lack of clear guidance on clinical pathways.6 Vascular patients are a group of patients with different characteristics. They tend to be of older age group with multiple co-morbidities and anaemia of different causes is common. Adding to this, vascular procedures tend to be semi-elective or urgent with not enough time to fully optimise the patient pre-operatively.

In conclusion, IV iron infusion can be a good option for treatment of preoperative patients with iron deficiency anaemia and can avoid the need for blood transfusion and its consequences. There is a need for more evidence regarding its efficacy in vascular patients.

\section{REFERENCES}

[1] Musallam KM, Tamim HM, Richards $\mathrm{T}$ et al (2011) Preoperative anaemia and postoperative outcomes in non-cardiac surgery: a retrospective cohort study. Lancet 378: 1396-407

[2] Baron DM, Hochrieser H, Posch M et al. (2014) Preoperative anaemia is associated with poor clinical outcome in non-cardiac surgery patients. Br J. Anaesth 113(3):416- 23

[3] Gross I, Seifert B, Hofmann A, Spahn DR. Patient blood management in cardiac surgery results in fewer transfusions and better outcome. Transfusion. 2015; 55:1075-1081

[4] Juffermans NP, Prins DJ, Vlaar AP, Nieuwland $\mathrm{R}$, Binnekade JM. Transfusion-related risk of secondary bacterial infections in sepsis patients: a retrospective cohort study. Shock. 2011; 35:355-359

[5] Vlaar AP, Juffermans NP. Transfusion-related acute lung injury: a clinical review. Lancet. 2013; 382:984-994.

[6] Munoz et al. (2017) International consensus statement on the peri-operative management of anaemia and iron deficiency. Anaesth. 72(2):233247 
Early Experience with IV Iron Preoptimisation in Critical Ischaemia (Case Series)

[7] European Medicines Agency. New recommendations to manage risk of allergic reactions with intravenous iron-containing medicines. http://www.ema.europa.eu/ema/ index.jsp? curl=pages/news_and_events/ news $/ 2013 / 06 /$ newsdetail_001833. jsp\&mid= WC0b01ac058004d5c1(accessed 01/08/2016).

Citation: Ahmed Nassar, Stacey Kerr, Bryce Renwick. Early Experience with IV Iron Preoptimisation in Critical Ischaemia (Case Series). Archives of Anesthesiology. 2019; 2(2): 05-07

Copyright: (C) 2019 : Ahmed Nassar, Stacey Kerr, Bryce Renwick. This is an open access article distributed under the Creative Commons Attribution License, which permits unrestricted use, distribution, and reproduction in any medium, provided the original work is properly cited. 